\title{
Ambiente Vivo e Unijuí FM, uma trajetória em defesa do ambiente natural nas ondas do rádio ${ }^{1}$
}

\author{
Janaíne KRONBAUER ${ }^{2}$ \\ Juliana GOMES ${ }^{3}$
}

Resumo:

Ainda há muito a ser feito para que sejam levadas ao público ouvinte informações de qualidade sobre o meio ambiente. Por todo o país o cenário é bastante árido, sendo escassas as produções jornalísticas relativas ao ambiente natural. Contribuindo para tornar menos turvo este cenário, a emissora de rádio Unijuí FM - 106.9, abriu espaço em sua grade para a veiculação de um programa voltado exclusivamente a esse tema, o Ambiente Vivo. Com uma postura bem definida em favor da preservação, o programa levou ao ar uma proposta diferente daquela que preconiza a imparcialidade jornalística. É acerca desse programa e sua trajetória, a partir de um estudo de caso, que este artigo se debruça. Por meio do acesso a documentos institucionais e entrevistas semiestruturadas com agentes envolvidos com a realização do programa, buscou-se fazer o registro documental e recuperar a importância da efetivação de práticas jornalísticas responsáveis para com a sociedade e o entorno que a acolhe, o ecossistema.

Palavras-chave: Radiojornalismo. Jornalismo ambiental. Registro documental. Ambiente Vivo. Unijuí FM.

\section{Ambiente Vivo and Unijuí FM, a trajectory in defense of the natural environment in the radio}

\begin{abstract}
:
There is still a lot to be done to bring quality information about the environment to the listening public. Across the country, the scenario is quite arid, with little production of journalism related to the natural environment. Contributing to make this scenario less murky, the radio station Unijuí FM - 106.9, opened space on its grid for the broadcast of a program exclusively dedicated to this theme, Ambiente Vivo. With a well-defined stance in favor of preservation, the program aired a proposal different from the one that advocates journalistic impartiality. It is about this program and its trajectory, from a case study, that this article focuses. Through access to institutional documents and semi-structured interviews with agents involved in carrying out the program, we sought to make documentary records and recover the importance of implementing responsible journalistic practices for society and the environment that welcomes it, the ecosystem.
\end{abstract}

Keywords: Radiojournalism. Environmental journalism. Documentary record. Ambiente Vivo. Unijuí FM.

\footnotetext{
${ }^{1}$ Este artigo foi produzido a partir da revisão e ampliação de sua versão original, inicialmente apresentada no $10^{\circ}$ Encontro Nacional de História da Mídia (GT História da Mídia Sonora), na Universidade Federal do Rio Grande do Sul - UFRGS, em Porto Alegre, entre 03 e 05 de maio de 2015.

2 Jornalista. Doutoranda em Jornalismo no Programa de Pós-graduação em Jornalismo da Universidade Federal de Santa Catarina (UFSC), com bolsa CAPES-DS. Mestre em Comunicação e Informação pela Universidade Federal do Rio Grande do Sul (UFRGS).E-mail: ksjanaine@gmail.com

${ }^{3}$ Jornalista. Mestre em Jornalismo pelo Programa de Pós-graduação em Jornalismo da Universidade Federal de Santa Catarina (UFSC). E-mail: jugomes250380@gmail.com.
} 


\title{
Ambiente Vivo y Unijuí FM, una trayectoria en defensa del medio ambiente en las ondas del radio
}

\begin{abstract}
Resumen:
Hay mucho por hacer para el público oyente obtener información de calidad sobre el medio ambiente. En todo el país, el escenario es bastante árido, con poca producción de periodismo relacionado con el medio ambiente. Contribuyendo a hacer este escenario menos turbio, la estación de radio Unijuí FM - 106.9, abrió espacio en su red para la transmisión de un programa dedicado exclusivamente a este tema, Ambiente Vivo. Con una postura bien definida a favor de la preservación, el programa emitió una propuesta diferente de la que aboga por la imparcialidad periodística. Se trata de este programa y su trayectoria, a partir de un estudio de caso, en el que se centra este artículo. A través del acceso a documentos institucionales y entrevistas semiestructuradas con agentes involucrados en la ejecución del programa, buscamos hacer registros documentales y recuperar la importancia de implementar prácticas periodísticas responsables para la sociedad y el medio ambiente que lo acoge, el ecosistema.
\end{abstract}

Palabras clave: Radioperiodismo. Periodismo ambiental. Registro documental. Ambiente Vivo. Unijuí FM.

\section{Uma mirada inicial sobre radiojornalismo e meio ambiente}

Campo para o exercício da prática profissional com a consequente produção de conhecimentos acerca da realidade (GENRO FILHO, 2012), o Jornalismo descreve sua trajetória de modo peculiar. Colaborando para a estruturação e registro histórico de acontecimentos, sua função também é a de fazer saber, pensar e refletir sobre o contexto que cerca a sociedade e os eventos nela/por ela protagonizados. Aqui se inserem a perspectiva das organizações vinculadas à comunicação e também do chamado Jornalismo Ambiental que, há tempos praticado, somente há pouco passou a ser entendido como de relevância mais acentuada frente à agenda dos grandes meios de comunicação. Corrobora essa leitura, a proposição de Meditsch $(2018$, p. 6) de que "a consciência ambiental vem sendo construída em nosso país há poucas décadas, que se refletem na maneira como o jornalismo trata a questão".

Quanto ao contexto das organizações, aqui fazemos referência à emissora de rádio de perfil universitário educativo Unijuí FM - 106.9. Em operação desde 2001, a emissora está vinculada à Fundação de Integração e Desenvolvimento do Noroeste do Estado do Rio Grande do Sul - FIDENE. Mantida por esta Fundação, o veículo pode ser enquadrado, segundo McLeish (2001), como de "propriedade institucional" - com vistas ao benefício dos indivíduos de alguma forma vinculados a ela, constituídos, neste caso, prioritariamente pela comunidade acadêmica, composta pelos corpos discente, docente e de colaboradores. A partir do perfil da emissora, é possível identificar o porquê de algumas das escolhas, inclusive editoriais, pelas quais optou a rádio.

A Unijuí FM levou ao ar de 2001 a 2013 o programa jornalístico Ambiente Vivo. 
Mesmo que hoje não seja mais veiculado, entendemos como necessário o registro e a recuperação de informações relativas ao programa, seja por seu ineditismo, seja para que sua historicidade não seja perdida. Passados 13 anos de sua existência, o programa foi reformulado e sua proposta diluída ao longo da programação da Unijuí FM. Em 2016, o Ambiente Vivo foi totalmente descontinuado. Assim, o que se pretende com este artigo é registrar alguns dos caminhos traçados pelo jornalístico ao longo desse período, motivo pelo qual realizamos um estudo de caso pontual, de perfil qualitativo, levantando informações junto a alguns dos profissionais que atuaram na emissora naquele período.

\section{Jornalismo no rádio}

Como veículo de comunicação, o rádio apresenta características que variam conforme o perfil da emissora, mas que, em linhas gerais, vinculam-se ao seu dinamismo, instantaneidade, baixo custo de operacionalização, possibilidade de estreito vínculo com o local, mobilidade, sensorialidade e, cada vez mais, a interação com o ouvinte (MCLEISH, 2001; ZUCULOTO, 2012). Pela linguagem sonora, como explicam Ortriwano (1985) e Zuculoto (2012), o rádio apresenta sua principal distinção em relação aos demais meios. Com isso, apenas um sentido, o da audição, é exigido do receptor. Por recorrer a esses predicados, um público amplo pode ter acesso aos conteúdos difundidos pelo meio, incluindo até aqueles que não sabem ler e não têm possibilidade de consumir informações reunidas em outras modalidades de texto. A sonoridade do rádio é interpretada por McLeish (2001) como uma vantagem, pois com a voz humana é possível explorar a sensibilidade da audiência e até conquistar sua confiança.

Considerando-se o atual cenário de convergência, é igualmente possível explorar outros sentidos, com o uso do recurso da imagem de vídeo, transmissões em tempo real, por sites de redes sociais ou das próprias emissoras, fotos captadas no local da pauta e o próprio texto verbal. Essa gama de recursos amplia a abrangência do rádio; a linguagem sonora, no entanto, continua sendo o seu principal predicado.

O imediatismo é uma característica marcante do veículo (ORTRIWANO, 1985; ZUCULOTO, 2012); com ela é possível transmitir os fatos no instante em que ocorrem. De acordo com Ortriwano (1985, p. 80), o imediatismo traz o mundo ao ouvinte, enquanto os fatos se dão. Contemporaneamente, agrega-se a esse atributo a possibilidade das conexões $4 \mathrm{G}$ e wireless - com elas, o rádio passa a ter muito mais agilidade. Esse entendimento reitera a 
proposição de Ortriwano (1985), que indica ser a instantaneidade uma característica inerente ao meio, sendo preciso indicar que enquanto o imediatismo trata da recepção, a instantaneidade refere-se à transmissão.

Pela instantaneidade se dá a linguagem do meio. Como destacam Almeida e Magnoni (2010), ao ouvinte não é possível repetir os conteúdos que chegam pelas ondas do rádio. A respeito dessa questão, Ferrareto (2001) menciona a fugacidade da mensagem radiofônica, pois ao ouvinte não é permitido conferir o conteúdo do rádio no momento da transmissão. Há, nesse caso, uma obsolescência da informação, ou seja, no momento de sua transmissão, ela já se torna pretérita, pois no rádio espera-se que a informação seja sempre o mais atual possível.

Exatamente em razão da fugacidade, se justifica a exigência da apresentação de conteúdos objetivos e claros. A fugacidade deixa de ser um demérito na medida em que a internet passa a funcionar como uma ferramenta para armazenar conteúdos na rede, como sugerido por Mielniczuk (2003). A web proporciona uma recuperação da informação. Nesse contexto, é possível destacar, ainda, os próprios podcasts, que, para Lopez (2010), proporcionam uma nova lógica de consumo dos conteúdos, permitindo que a web atue como um arquivo das produções radiofônicas ou, mesmo, um repositório.

O rádio contemporâneo estabelece uma individualização da programação, como afirma Zuculoto (2012). O público que confere seus conteúdos é mais abrangente, sendo que a ele é, inclusive, permitido fazer sua própria programação de rádio, voltada exclusivamente para os seus interesses particulares. Para aproveitar essa tendência, muitas emissoras exploram recursos como newsletters, que atendem às escolhas do usuário.

Como indica Zuculoto (2012), a abrangência também é uma das características do veículo. Ortriwano (1985) prefere chamá-la de penetração. Tal peculiaridade é apontada pelas estudiosas como a extensão do alcance do meio, algo potencializado pela internet. Assim, conforme Kischinhevsky (2007), populações localizadas em pontos remotos do globo podem acompanhar a programação de emissoras de diversos países. Esse fenômeno impacta diretamente nas emissoras locais que, acostumadas a transmitir para pequenas comunidades, passam a comunicar para um público muito mais amplo via internet. Com isso, essas rádios são inseridas em um cenário geográfico mais amplo e passam a produzir conteúdos de caráter "glocal"4 (RADDATZ, 2009).

Ortriwano (1985) e Zuculoto (2012) indicam também como característica do veículo seu baixo custo de produção e recepção, se comparado a outros meios como a televisão, por

\footnotetext{
${ }^{4} \mathrm{O}$ termo é usado para referir o esforço feito pelo Jornalismo para compreender/retratar a realidade local de uma comunidade inserida num contexto global (RADDATZ, 2009).
} 
exemplo. A convergência chama a atenção para os custos reduzidos de produção, sobretudo, quando há integração de redações e a consequente redução/supressão de equipes. ${ }^{5}$

A sensorialidade, que qualifica a capacidade de envolver o ouvinte com o meio e que estabelece uma espécie de diálogo mental com o emissor, também é apontada por Ortriwano (1985) e Zuculoto (2012) como uma das características do rádio. No contexto das tecnologias digitais, a sensorialidade se amplia pela adição de recursos visuais como os de vídeo e de fotografia. Lopez (2009), ao se referir ao vídeo usado nos sites das emissoras de rádio, considera-o como um recurso que amplia a informação para o usuário da rede, reforçando a ambientação da pauta.

Ainda é preciso considerar a autonomia do rádio. Para Ortriwano (1985), essa característica permite o consumo individual de conteúdos e, com isso, o público pode acompanhar a programação em qualquer local, mesmo enquanto executa outra tarefa. Para Medistch (2007), a recepção radiofônica tem um caráter secundário. Quando ouve rádio ao mesmo tempo em que desenvolve outra atividade, o ouvinte convive com o que o autor denomina de zoom auditivo e zapping perceptivo. No primeiro, há uma variação de concentração dedicada ao conteúdo sonoro. Esta pode ser diferenciada entre ouvir com atenção e escutar com relativo desinteresse. No caso do zapping perceptivo, há uma variação na atenção durante a audição do rádio, entrecortada pela execução de alguma tarefa, como a doméstica, por exemplo. Se considerarmos o rádio na internet, ainda de acordo com Meditsch (2007), o veículo passa a competir com um número muito maior de opções em entretenimento, pois ao mesmo tempo em que acompanha a programação de uma emissora na internet, por exemplo, a audiência pode fazer pesquisas em outros sites em busca de diversidade informativa ou, mesmo, maior profundidade acerca das informações fornecidas pelo rádio.

Cebrián Herreros (2008) acrescenta outro olhar sobre essa questão. Ele entende que o rádio transmitido pela internet se distingue daquele que chega ao ouvinte pelas ondas hertzianas. Nesse novo ambiente há alterações na linguagem, nos formatos e na interação proporcionada. O autor entende que há uma ampliação do conceito de rádio, pois este passa a dispor de conteúdos para serem vistos, permitindo intervenções orais ou escritas do público. Assim, pode-se afirmar que, no contexto de convergência, o rádio agrega outras linguagens

5 Exemplo ilustrativo é o da plataforma Gaúcha ZH, em vigor desde setembro de 2017: http://www.gruporbs.com.br/noticias/2018/09/21/gauchazh-celebra-um-ano-com-mais-de-147-milhoes-deusuarios/ 
estabelecidas a partir de redes sociais, sites, aplicativos para dispositivos móveis e celulares, vídeos e fotos.

Para Ortriwano (1985) e Zuculoto (2012), a mobilidade também é uma das principais características do rádio. As autoras observam que, para o veículo e para o público, esse potencial tem implicações diferentes. Diretamente relacionada a avanços tecnológicos (como o desenvolvimento de unidades móveis, de gravadores magnéticos e, principalmente, de transistores), a partir da mobilidade, a programação radiofônica passa a estar disponível não apenas no aparelho de rádio ou no radinho de pilha, mas também em telefones celulares. Com isso, o conteúdo radiofônico pode ser acessado via computadores portáteis, como tablets e smartphones. Assim, do ponto de vista do consumo, o rádio se potencializa.

Hoje o veículo pode ser ouvido tanto pela captação de ondas eletromagnéticas, tendo os fones de ouvido como antena receptora, quanto por meio da internet, via dispositivos móveis, o que permite a recepção do sinal digital de rádio ou, ainda, por aplicativos. No primeiro caso, há a barreira geográfica imposta pelo sinal analógico. Outra limitação é o fato de o celular captar apenas as emissoras FM. Desde 2013, no entanto, autoridades brasileiras (VERDÉLIO, 2018) passaram a permitir que as rádios em amplitude modulada (AM) migrem para a FM, pois essas estações estavam sendo prejudicadas por não poderem ser ouvidas em dispositivos móveis.

A partir dessa contextualização em torno do rádio contemporâneo e suas características, pode-se visualizar seu impacto no exercício do Jornalismo. Uma vez praticado de modo a satisfazer (ainda que minimamente) tais premissas, o veículo assume novamente relevância singular. Sobre a tentativa de consorciar tais peculiaridades com a prática do Jornalismo voltado à esfera ambiental é que avançamos nas linhas a seguir.

\section{Unijuí FM e a opção pelo programa Ambiente Vivo}

Nas regiões de interior, como a que aqui faremos referência - a Noroeste do Rio Grande do Sul -, o rádio enquanto veículo que comunica para a massa descreve uma trajetória peculiar. Devido a seu fácil acesso e amplo alcance, o meio se apresenta como um espaço legitimado e, por assim dizer, tradicional diante da audiência. A exemplo do que já ocorreu (e ainda ocorre) em vários lugares do país, o meio já foi a única forma de se ter acesso às informações sobre o que acontecia no Brasil ou, mesmo, no mundo, nessa região.

A partir das características e possibilidades acima indicadas, o rádio instigou em uma 
entidade de perfil comunitário, a FIDENE, a vontade de possuir uma concessão de emissora de rádio educativa. Prioritariamente vinculada ao fomento do desenvolvimento socioeconômico daquela região e à oferta de ensino superior, a instituição, por meio de uma de suas mantidas, ${ }^{6}$ buscou obter desde 1992, junto ao Ministério da Educação, uma concessão de emissora de rádio educativa ${ }^{7}$, o que somente se efetivou em 2001 (RADDATZ, 2015; BERGER, 2015). A partir da concessão passou a funcionar a Rádio e Televisão EducativaRTVE.

Conforme informado por Berger (2015), a emissora teve um período inferior a um ano para definir de sua grade de programação até a constituição de sua equipe, passando ainda pela estruturação técnica e conformação de sua identidade. No período de 16/06 a 19/07/2001, a rádio Unijuí FM entrou no ar em caráter experimental, sendo inaugurada oficialmente em 20/07/2001. O período inicial teve várias reuniões entre a equipe de profissionais contratados, a Direção e o Conselho da emissora, com vistas à estruturação de uma rádio que atendesse aos anseios da Fundação e também levasse aos ouvintes produtos com qualidade de programação diferenciada.

O ex-Diretor da RTVE, o jornalista Luiz Henrique Berger (2015), que acompanhou a estruturação da emissora desde 2001, quando atuava como Coordenador Operacional de Radiodifusão, explica:
A pauta ambiental desde o início foi definida como prioritária pelo simples fato de que é prioritária, ao lado de educação, cidadania, ciência e tecnologia; saúde e qualidade de vida; política e políticas públicas; economia e relações de consumo; direitos humanos, questões de gênero e de minorias; trabalho. Como rádio ligada à Universidade, desde o início esteve muito claro para a equipe e direção que deveríamos nos empenhar e dedicar tempos generosos para os assuntos ligados à natureza.

Considerando o contexto organizacional da emissora, cabe informar que a missão da Unijuí FM, em consonância com a da Fundação e suas demais mantidas, é assim definida: "Proporcionar ao público a compreensão crítica da realidade, mediante uma programação interativa e sensível às causas de interesse coletivo e aos elementos constitutivos da identidade regional" (SOBRE... s.d). Possivelmente a partir dos elementos contidos nessa missão, a rádio tenha adotado desde o início, como premissa, o cuidado e o pioneirismo em

\footnotetext{
${ }^{6}$ A FIDENE mantém, além da emissora de rádio, outras três estruturas: Universidade Regional do Noroeste do Estado do Rio Grande do Sul-UNIJUÍ, Museu Antropológico Diretor Pestana-MADP e Centro de Educação Básica Francisco de Assis-EFA.

${ }^{7}$ A concessão de canais de radiodifusão para emissoras de rádio educativas passa por um trâmite legal próprio, não sujeito à publicação de edital específico, como no caso das emissoras comerciais. Mesmo assim, o processo para a concessão do canal de rádio para a instauração da Unijuí FM tramitou por 10 anos.
} 
tratar de um assunto que abrange todos os demais, mas que fica alijado, relegado a um segundo plano diante do contexto social: o meio ambiente.

Desde o início na grade da emissora, o Ambiente Vivo tinha duração de 30 minutos. Produzido, gravado e editado ao longo da semana, o programa era veiculado nas manhãs de sábado, às $9 \mathrm{~h}$, e reprisado no domingo, em horário alternativo. Sua equipe era bastante reduzida: apenas um jornalista produzia, apresentava e editava o programa (eventualmente, com a colaboração de algum estagiário), com o auxílio de um técnico de áudio, responsável pela edição final. Ao menos cinco jornalistas profissionais foram responsáveis pelo programa em seus quase 13 anos de existência, realizando entrevistas com especialistas da área ambiental, reportagens especiais, boletins, notas e comentários.

As pautas, mesmo as nacionais e/ou internacionais, procuravam ser abordadas a partir de seu vínculo com o local, com seus efeitos e reverberações. Da transgenia e agrotóxicos ao plantio de pinus e eucalipto com a desertificação, o desmatamento, a valorização da agricultura familiar, a importância da conservação de mananciais como o Aquífero Guarani ou a poluição dos rios da região, a erosão do solo, o tratamento de água, esgoto e efluentes da cidade e a necessidade legal de adequação dos conhecidos "lixões" para aterros sanitários estes foram alguns dos assuntos que receberam destaque a partir do olhar criterioso do programa, que dava voz a fontes diretamente envolvidas com questões ambientais e que dispunham de conhecimento a ser compartilhado. A posição política do programa em relação a cada uma das pautas tratadas era sempre tornada evidente.

O jornalismo ambiental praticado pela Unijuí FM, por meio do Ambiente Vivo, se relaciona diretamente ao que propõe Bueno (2008) ao articular, em uma mesma equação, fatores que visualiza como primordiais para o êxito das práticas em torno do jornalismo ambiental.

O jornalismo Ambiental é, antes de tudo, jornalismo (que é o substantivo, o núcleo da expressão) e deve ter compromisso com o interesse público, com a democratização do conhecimento, com a ampliação do debate. Não pode ser utilizado como porta-voz de segmentos da sociedade para legitimar poderes e privilégios (BUENO, 2008, p. 111).

Sabe-se que, como profissão, o Jornalismo busca zelar por critérios como o da objetividade, o espaço para o contraditório, a diversidade de fontes, dentre outros. No caso do Ambiente Vivo, a postura adotada foi, na maior parte das vezes, diferente desta, em benefício da preservação da vida. O jornalismo ambiental praticado a partir dele teve como base uma 
posição política voltada para a ética do cuidado, a qual foi assumida por todos os jornalistas que passaram pelo programa. Nas palavras do ex-Diretor da emissora,

[...] o programa se posicionava a favor da vida [...]. Sempre buscava como fontes estudiosos, pesquisadores com um olhar diferenciado comparado ao que a grande imprensa e até os meios da cidade e região oferecem. Esse é o nosso papel como rádio de caráter educativo (BERGER, 2015).

Reforçando essa proposição, a jornalista e pesquisadora Vera Raddatz, que no início da Unijuí FM atuava na sua Coordenação Pedagógica, atesta:

[...] o Ambiente Vivo não era neutro, ao contrário, pretendia-se chamar a atenção da comunidade para o direito à vida, à responsabilidade que cada cidadão tem em proteger e cuidar do lugar onde está no mundo, não importa se seja o poço de água no interior ou a horta comunitária urbana ou, ainda, a pesquisa produzida em ambiente acadêmico (RADDATZ, 2015).

Associam-se a essas considerações alguns valores que dão o tom do compromisso desse campo do jornalismo e que eram facilmente identificados no programa, com destaque para a busca pela efetivação da cidadania e a ação educativa para a formação dos sujeitos. Nesse sentido, o Ambiente Vivo atendia às funções básicas que qualificam o Jornalismo Ambiental, apontadas por Bueno (2008, p.109): “[...] 1) a função informativa; 2) a função pedagógica e 3) a função política". 8

A veiculação do programa ocorreu a partir de um posicionamento muito evidente, associada a um intenso compromisso com a responsabilidade social e pedagógica da emissora. Jornalista responsável pelo programa à época de sua criação, Reges Schwaab, já em 2005, propunha:

Cumprir essa missão levanta a necessidade de não reforçar o estigma de que meio ambiente é sinônimo de fauna e flora ou tocar na pauta quando mais um acidente ecológico aconteceu, quando se vende madeira ilegalmente ou, ainda neste barco, com matérias jornalísticas enfocando a natureza apenas pela via da contemplação. A informação de tragédias, ainda que indiretamente sensibilize uma parcela da população ou cobre atitudes de autoridades, é pouco reflexiva em relação às causas e possíveis alternativas

\footnotetext{
${ }^{8}$ Ao referenciar as três funções do Jornalismo Ambiental, Bueno (2008, p. 110) explica que a função informativa "[...] preenche a necessidade que os cidadãos têm de estar em dia com os principais temas que abrangem a questão ambiental" considerando, para isso, o impacto gerado por posturas, processos e modelos "sobre o meio ambiente e, por extensão, a sua qualidade de vida". No caso da função pedagógica, o autor entende que ela se refira "[...] à explicitação das causas e soluções para os problemas ambientais e à indicação de caminhos [...] para a superação dos problemas ambientais". Finalmente, a função política diz respeito à "mobilização dos cidadãos para fazer frente aos interesses que condicionam o agravamento da questão ambiental", englobando, nesse espectro, dentre outros, interesses de empresas, grupos econômicos, ação e omissão de entes públicos e governamentais.
} 
para o que se apresenta, trazendo uma visão fragmentada da questão (SCHWAAB, 2005).

O Ambiente Vivo e também os demais programas com viés jornalístico da Unijuí FM por muito tempo não tiveram uma preocupação central com índices de audiência, diferentemente do que ocorre com emissoras de perfil comercial.

Não pensávamos na lógica do retorno em termos de audiência. Alguns assuntos eram tidos como essenciais, caso, por exemplo, do ambiente. A ideia era oferecer conteúdos que levassem à reflexão, entrevistas com autoridades em assuntos ligados ao meio ambiente (BERGER, 2015).

Buscar ser agente de transformação social era a tônica que mobilizava as produções da emissora universitária de perfil educativo.

Sabia-se das dificuldades de conquistar um público ouvinte que não representava a "massa" ou a maioria. Julgávamos fazer uma programação de qualidade que envolvesse todos os aspectos de uma rádio educativa, que incluía a educação para o meio ambiente (RADDATZ, 2015).

Essa lógica somente foi possível porque, do mesmo modo que sua mantenedora, a Unijuí FM não objetivava o lucro, apenas a autossuficiência. ${ }^{9}$ Cada vez mais, no entanto, tal perspectiva se constitui em um desafio para qualquer veículo de comunicação. Hoje, além da manutenção financeira, o atual cenário de convergência das mídias exige que as emissoras de rádio, para que possam se manter, adaptem-se, o que inclui também formatos de programas e conteúdos. Com a Unijuí FM não foi diferente e é acerca dessa outra dimensão que avançamos a seguir.

\section{Rádio e Jornalismo Ambiental frente à tecnologia digital}

O surgimento do rádio se dá em resposta à busca humana por uma comunicação cada vez mais eficiente. Desta forma, as transformações que o perpassam se inserem nesse anseio dos sujeitos por facilidades para emitir mensagens e informações. A característica que possivelmente mais bem defina o veículo é a versatilidade, pois, mesmo hoje, prestes a completar um século, o meio uma vez mais se reinventa e adapta. Aqui nos referimos à digitalização e convergência dos meios e à própria horizontalização do acesso à possibilidade de compartilhamento de informações por parte dos ouvintes.

\footnotetext{
${ }^{9}$ A legislação das emissoras de rádio educativas impede que anúncios comerciais sejam feitos na programação, sendo veiculados, em spots ou jingles, apenas apoios culturais com informações institucionais dos apoiadores (BRASIL, 2007).
} 
Ao introduzir a discussão em torno desse aspecto, Prata (2012, p.15) questiona:

O rádio de uma era que é chamada de pós-modernidade tem imagens em movimento, fotografias, links, interação em tempo real e não linearidade. Mas o rádio na internet, continua sendo rádio? Ou é uma nova mídia sem definição? Certamente a linguagem é o ponto-chave desta discussão.

Hoje vivemos uma época em que o acesso à informação deixou de ser verticalizado, partindo exclusivamente de um polo emissor para a audiência. No caso do rádio, a partir de sua interatividade, algumas experiências já ocorriam, mas hoje, com as redes sociais virtuais, tal processo se ampliou. A convergência, de que trata Jenkins (2009), é contínua e tem reflexos na própria segmentação de produtos e serviços.

$\mathrm{Na}$ busca por se ajustar a essa nova perspectiva convergente, caracterizada de modo complementar por Anderson (2006) a partir do conceito de Cauda Longa, ${ }^{10}$ também o rádio se beneficia. Como avaliza Prata (2012, p. 25), “fazer rádio na web proporciona o surgimento de emissoras voltadas a nichos altamente seletivos, multiplicando o número de estações". A segmentação já estava presente na rotina das emissoras de rádio hertzianas e, no caso da Unijuí FM, por seu perfil educativo, essa característica também fora marcada de antemão.

As possibilidades colocadas pela virtualidade também abriram caminho para que novos recursos passassem a ser utilizados no sentido de ampliar a experiência do ouvinte com o veículo rádio, mas como esclarece Medistch (2001 apud PRATA, 2012), a unidade básica do rádio é a transmissão de áudio. O autor assim define o veículo: "Meio de comunicação que transmite informação sonora, invisível, em tempo real. A informação sonora poderá vir acompanhada de textos e imagens, mas estes não serão necessários para a compreensão da transmissão" (MEDITSCH, 2001 apud PRATA, 2012, p. 74).

Para atender àquilo que o público anseia na época da modernidade líquida (BAUMAN; DONSKIS, 2014), são experimentadas novas roupagens e incorporados novos formatos de produções para tornar os materiais mais fluidos e diluídos ao longo da programação das emissoras. $\mathrm{O}$ advento da internet ocasionou a construção de um novo modelo de radiofonia e, além dos desafios à adaptação, o veículo viu elementos novos serem agregados ao seu contexto produtivo:

\footnotetext{
${ }^{10}$ Originário da Economia, o conceito de Cauda Longa trata de uma mudança comportamental do público. Se antes a informação era consumida a partir de uma ótica vertical (emissão $\rightarrow$ recepção), hoje há possibilidades diversas e o consumidor é muito mais protagonista em suas escolhas (ANDERSON, 2006).
} 
[...] o usuário não apenas ouve as mensagens transmitidas, mas também as encontra em textos, vídeos, fotografias, desenhos, hipertextos. Além do áudio, há toda uma profusão de elementos textuais e imagéticos que ressignificam o velho invento de Marconi (PRATA, 2012, p. 43).

Em relação ao registro que aqui propomos, cabe destacar que a Unijuí FM buscou, em termos gerais, uma reconfiguração. No caso do Ambiente Vivo, depois de 13 anos de veiculação, a emissora entendeu que o formato concentrado já não era o mais adequado para alcançar o que a rádio ambicionava: a abordagem de conteúdos voltados ao tema a partir de toda a programação.

A proposta do programa foi então desmembrada em três vértices: 1) Ações Sustentáveis (programete com dicas sobre meio ambiente, preservação, uso racional de água e energia elétrica, etc.); 2) Ações Sustentáveis nas Escolas (projeto realizado em conjunto com 15 educandários do município); e 3) Ambiente Vivo ${ }^{11}$ (espaço jornalístico reconfigurado com produções cujo tempo variava entre três e cinco minutos, apresentando, também, entrevistas curtas). Conforme relato Coordenadora Pedagógica da Unijuí FM, Carine Prediger Da Pieve (2018), essas foram as alternativas encontradas para que as questões referentes ao ambiente natural pudessem estar presentes ao longo de toda a programação e também extrapolando as suas dimensões, seja no dial ou na web.

O ex-Diretor da Unijuí FM, Luiz Henrique Berger, à época um dos principais responsáveis pelas mudanças na configuração do Ambiente Vivo, afirma:

Entendi (e no caso a proposta foi minha) que o modo de ouvir rádio mudou. O olhar foi para um ouvinte que sintonizando a Unijuí FM [...] pudesse ouvir uma boa música e uma informação que chamasse a atenção ou que pelo menos fosse num formato que não o fizesse trocar de emissora. O que discutimos e passa por uma mudança são os conteúdos do Ações [Sustentáveis], que começaram a ter [...] dicas para práticas rotineiras, a partir de pesquisas em sites especializados e com professores da Universidade (BERGER, 2015).

Apesar das mudanças realizadas com o desmembramento do programa em três ações distintas, ele foi descontinuado em março de 2016. Para Da Pieve (2018), a mudança não representa a ausência de destaque à pauta ambiental na programação da emissora, pelo contrário: “[...] as informações sobre meio ambiente são abordadas na programação de forma integral, não tendo um horário específico para ser priorizada".

\footnotetext{
${ }^{11}$ Neste formato, o Ambiente Vivo foi veiculado às terças e quintas-feiras (às 8h30min e às $13 \mathrm{~h}$ ); aos sábados (às $9 \mathrm{~h}$ e às $12 \mathrm{~h} 30 \mathrm{~min}$ ) e aos domingos (às $9 \mathrm{~h}$ e às $13 \mathrm{~h}$ ).
} 
Alves (2003 apud PRATA 2012) propõe que o rádio de hoje está entrecortado por quatro fases distintas quanto à digitalização (intersecção, adaptação, mudança e transformação). Paralelamente, Cébrian Herreros (2008) aponta três modelos de classificação para o meio (generalista, temático e convergente), sendo, de certa forma, contestado por Campos e Pestano (2006 apud PRATA, 2008), os quais entendem que o terceiro modelo proposto por Cébrian Herreros ainda não existe.

Se não há unanimidade quanto ao formato que hoje o veículo assume, o que se pode afirmar é que a adaptação é um matiz constante no que se refere ao rádio. Para Prata (2012), o termo que mais bem define a etapa atual da radiofonia (analógica e digital) é o conceito de radiomorfose, o qual se refere ao momento de avanço e recuo ainda possível de identificar quanto às alternativas colocadas ao veículo no contexto da digitalização.

Del Bianco (2006 apud PRATA, 2012, p. 53) propõe:

\begin{abstract}
O rádio digital é uma revolução técnica tão significativa que irá alterar o modo de produção da programação, de distribuição de sinais e a recepção da mensagem radiofônica. Pesquisadores da área de várias partes do mundo apontam para a necessidade de uma "reinvenção" do rádio para que possa se adaptar à nova tecnologia. A mais evidente reinvenção está relacionada à diversificação do conteúdo para atender ao crescimento da oferta decorrente da diversificação de modalidades de canais.
\end{abstract}

Neste momento, aludimos ao trabalho realizado pela Unijuí FM, em específico, a partir do programa Ambiente Vivo, que buscou caminhar nesse sentido. Hoje, a emissora busca tratar do tema ambiental em diferentes momentos da programação por entendê-lo como relevante e, para isso, apostou em uma estratégia que pode até ser considerada ousada, com a ampliação dos espaços destinados à temática ao longo de sua programação.

\title{
Considerações finais
}

O rádio significa, essencialmente, transmissão em tempo real, imediata, instantânea, sem possibilidade de recuperação. Esta qualidade inerente ao veículo é, hoje, no entanto, entrecortada por elementos inexistentes há cerca de 20 anos, quando as emissoras tinham o compromisso de levar informação atualizada, sucinta e verossímil aos ouvintes, mas não de modo tão rápido e, até mesmo, superficial, por assim dizer.

$\mathrm{Na}$ atualidade, com a celeridade de processos em todos os campos da vida social, também o rádio foi afetado, pois uma rotina produtiva ainda mais veloz do que a usual é 
solicitada àqueles que se dispõem a fazê-lo. Nesse caminho, recuperamos a proposição feita por Prata (2012), quando a autora postula que o ponto-chave para o meio circula em torno da linguagem. A linguagem no rádio assume diferentes roupagens e, hoje, no caso aqui apresentado, o formato de um programa que vinha sendo considerado exitoso ${ }^{12}$ foi, mesmo assim, submetido a uma nova configuração. Isso demonstra que o meio permanece, mais uma vez, vivo, buscando alternativas para tornar perene sua trajetória.

Emissora comprometida com uma perspectiva mais ampla que a da sustentação econômico-financeira, a Unijuí FM inovou ao trazer para seu foco de ação questões caras ao ambiente natural, que impactam decisivamente na vida cotidiana - ainda que, em boa medida, a audiência sequer atente para isso. Esse entendimento vai ao encontro do que propõe Meditsch (2018, p. 6), quando afirma que o Jornalismo Ambiental constitui

[...] um novo paradigma para a formação geral dos jornalistas, como produtores intelectuais capazes de um pensamento sistêmico (ou dialético, diria Adelmo Genro Filho), que dê conta da complexidade do mundo social, da fragilidade do ambiente natural, da dimensão educativa da profissão e da Ética do Cuidado com que deve ser exercida.

Do ponto de vista do Jornalismo Ambiental, as lacunas a serem preenchidas pelos meios de comunicação (como um todo) são ainda bastante largas. Decorre disso nossa intenção de registrar essa iniciativa pioneira de uma emissora de rádio educativa, localizada numa região de interior e que, mesmo diante de dificuldades, assumiu como compromisso inerente à sua atuação, o compromisso com a causa ambiental.

\footnotetext{
${ }^{12}$ A Unijuí FM recebeu várias distinções por suas produções na área ambiental: em 2011, o Ambiente Vivo recebeu o Prêmio Ambiental Ben Hur Lenz César Mafra, na categoria imprensa; em 2013, tanto o Ambiente Vivo quanto o programete Ações Sustentáveis receberam a premiação; em 2014, a emissora foi uma das vencedoras do Prêmio Pioneiras da Ecologia, da Assembleia Legislativa do RS. O projeto Ações Sustentáveis recebeu, nos últimos anos, vários prêmios: em 2015, o Prêmio von Martius de Sustentabilidade, da Câmara de Comércio e Indústria Brasil-Alemanha; em 2016, mais uma edição do Prêmio Ben Hur Lenz César Mafra, na categoria imprensa, e também do Prêmio Pioneiras da Ecologia, da Assembleia Legislativa do RS. Em 2017, foi a vez do Prêmio Ozires Silva de Empreendedorismo Sustentável e ainda o Prêmio José Lutzenberger de Jornalismo Ambiental (DA PIEVE, 2018).
} 


\section{Referências}

ALMEIDA, Ana Carolina; MAGNONI, Antonio Francisco. Rádio e internet: recursos proporcionados pela web ao radiojornalismo. In: MAGNONI, Antonio Francisco; CARVALHO, Juliano Maurício de (org.). O novo rádio: cenários da radiodifusão na era digital. São Paulo: Senac: 2010. p. 273-290.

ANDERSON, Chris. A cauda longa: do mercado de massa para o mercado de nicho. Rio de Janeiro: Elsevier, 2006.

BAUMAN, Zygmunt; DONSKIS, Leonidas. Cegueira moral: a perda da sensibilidade na modernidade líquida. Rio de Janeiro: Zahar, 2014.

BERGER, Luiz Henrique. Perguntas - produção artigo - ALCAR. [mensagem pessoal] Mensagem recebida por: ksjanaine@gmail.com em: 10 abr. 2015.

BRASIL. Decreto-Lei $\mathbf{n}^{\mathbf{2}}$ 236, de 27 de fevereiro de 2007. Complementa e modifica a Lei número 4.117 de 27 de agosto de 1962. Disponível em: https://bityli.com/xuF6k. Acesso em: 08 mar. 2021.

BUENO, Wilson. Jornalismo ambiental: explorando além do conceito. In: GIRARDI, Ilza; SCHWAAB, Reges. (org.). Jornalismo ambiental: desafios e reflexões. Porto Alegre: Dom Quixote, 2008, p. 105-118.

CEBRIÁN HERREROS, Mariano. La radio en internet. Buenos Aires: La Crujía, 2008.

DA PIEVE, Carine Prediger. Informações Ambiente Vivo e Ações Sustentáveis na UNIJUI FM [mensagem pessoal] Mensagem recebida por: ksjanaine@ gmail.com em: 19 jul. 2018.

FERRARETTO, Luiz Arthur. Rádio: o veículo, a história e a técnica. 2. ed. Porto Alegre: Sagra Luzzatto, 2001.

GENRO FILHO, Adelmo. O segredo da pirâmide: para uma teoria marxista do jornalismo. Florianópolis: Insular, 2012.

JENKINS, Henry. Cultura da convergência. 2. ed. São Paulo: Aleph, 2009.

KISCHINHEVSKY, Marcelo. O rádio sem onda: convergência digital e novos desafios na radiodifusão. Rio de Janeiro: E-Papers, 2007.

LOPEZ, Débora. Marcos tecnológicos do radiojornalismo no Brasil: uma revisão histórica. In: KLÖCKNER, Luciano; PRATA, Nair (org.). A história da mídia sonora: experiências, memórias e afetos de norte a sul do Brasil. Porto Alegre: Edipucrs, 2009, p. 466-482.

MCLEISH, Robert. Produção de rádio: um guia abrangente de produção radiofônica. São Paulo: Summus, 2001.

MEDITSCH, Eduardo. Prefácio. In: GIRARDI, Ilza [et al.]. Jornalismo ambiental: teoria e prática. Porto Alegre: Metamorfose, 2018. 
MEDITSCH, Eduardo. O rádio na era da informação. 2. ed. Florianópolis: Insular, Editora da UFSC, 2007.

MIELNICZUK, Luciana. Jornalismo na web: uma contribuição para o estudo do formato da notícia na escrita hipertextual. 2003. Tese (Doutorado) - Curso de Doutorado em Comunicação e Culturas Contemporânea, Universidade Federal da Bahia, Salvador, 2003. Disponível em: https://repositorio.ufba.br/ri/handle/ri/6057. Acesso em: 06 jun. 2014.

ORTRIWANO, Gisela. A informação no rádio: os grupos de poder e a determinação dos conteúdos. São Paulo: Summus, 1985.

PRATA, Nair. Webrádio: novos gêneros, novas formas de interação. 2. ed. Florianópolis: Insular, 2012.

PRATA, Nair. Webrádio: novos gêneros, novas formas de interação. 2008. Tese (Doutorado em Linguística) - Faculdade de Letras, Universidade Federal de Minas Gerais, Belo Horizonte, 2008. Disponível em: https://repositorio.ufmg.br/bitstream/1843/AIRR7DDJD8/1/nair_prata_tese.pdf. Acesso em: maio de 2014.

RADDATZ, Vera. Perguntas - produção artigo ALCAR. [mensagem pessoal] Mensagem recebida por: ksjanaine@gmail.com em: 13 abr. 2015.

RADDATZ, Vera. Rádio de fronteira: da cultura local ao espaço global. 2009. Tese (Doutorado) - Programa de Pós-Graduação em Comunicação e Informação, Universidade Federal do Rio Grande do Sul, Porto Alegre, 2009. Disponível em: https://lume.ufrgs.br/handle/10183/15868. Acesso em: maio de 2014.

SCHWAAB, Reges Toni. Jornalismo Ambiental no rádio educativo: a experiência do programa Ambiente Vivo. In: ENCONTRO NACIONAL DA REDE ALFREDO DE CARVAlHO, 3., 2005, Novo Hamburgo. Anais [...]. Novo Hamburgo: 2005. Disponível em: http://www.ufrgs.br/alcar/encontros-nacionais-1/encontros-nacionais/3o-encontro-2005-1. Acesso em: 11 jul. 2018.

SOBRE Rádio Unijuí FM 106,9. Ijuí, [s.d.]. Disponível em: https://www.unijui.edu.br/unijuifm/sobre. Acesso em: 28 maio 2020.

VERDÉLIO, Andreia. Governo vai reabrir prazo para emissoras de rádio AM pedirem migração para FM. Agência Brasil, Geral, não paginado, 10 jan. 2018. Disponível em: http://agenciabrasil.ebc.com.br/pesquisa-e-inovacao/noticia/2018-01/governo-vai-reabrirprazo-para-emissoras-de-radio-am-pedirem. Acesso em: 20 maio 2020.

ZUCULOTO, Valci. No ar: a história da notícia de rádio no Brasil. Florianópolis: Insular, 2012.

Submetido em 20.12.2018

Aprovado em 13.01.2020 